\title{
2-Methyl 2-butanol suppresses human retinoblastoma cells through cell cycle arrest and autophagy
}

\author{
Xiangyun $\mathrm{Li}^{1}$, Xiangxiang $\mathrm{Zhu}^{2}$, Chong $\mathrm{Xu}^{1}$ and Jianhua $\mathrm{Wu}^{1}$ \\ ${ }^{1}$ Department of Fundus, Wuhan Aier Eye Hospital, Wuhan, Hubei Province, China \\ ${ }^{2}$ Ophthalmology Center, Renmin Hospital of Wuhan University, Wuhan, Hubei Province, China
}

\begin{abstract}
2-Methyl-2-butanol (MBT) is a chemical compound from the group of alcohols more specifically pentanols, which has shown an excellent anti-cancer activity in our previous study. However, its mechanism of action remains unclear. The present study was designed to investigate the anti-cancer effect of MBT on human retinoblastoma cells. The results showed that the use of MBT leads to HXO-RB44 cell death but is cytotoxic to normal cells at higher concentrations. It showed a dose- as well as a timedependent inhibition of HXO-RB44 cells. P27 is a cell cycle inhibitory protein, which plays an important role in cell cycle regulation whereas cyclin-B1 is a regulatory protein involved in mitosis. MBT increased the cell cycle arrest in a dose-dependent manner by augmenting p27 and reducing cyclin B1 expression. Moreover, it also accelerated apoptosis, increased light chain-3 (LC-3) conversion in a dose-dependent manner, and helped to debulk cancerous cells. LC3 is a soluble protein, which helps to engulf cytoplasmic components, including cytosolic proteins and organelles during autophagy from autophagosomes. In order to verify the effect of MBT, bafilomycin A1, an autophagy inhibitor, was used to block the MTB-induced apoptosis and necrosis. Additionally, a specific Akt agonist, SC-79, reversed the MBT-induced cell cycle arrest and autophagy. Thus, from the present study, it was concluded that MBT induced cell cycle arrest, apoptosis and autophagy through the PI3K/Akt pathway in HXO-RB44 cells.
\end{abstract}

Key words: 2-methyl-2-butanol; Retinoblastoma; Cell cycle arrest; Autophagy; Phosphoinositide 3-kinase (PI3K)/Akt

\section{Introduction}

Retinoblastoma is a pediatric cancer of the retina most often caused by inactivation of the retinoblastoma tumor suppressor gene. It is a serious health problem as well as a threat to life. It is caused by a hereditary genetic defect as well as congenital mutation in the chromosome 13 . Though most children survive this cancer, they may lose their vision in the affected eye or need to have the eye removed. There are various risk factors such as age, genetics, environment, and lifestyle, which affects the incidence of retinoblastoma in the world. According to World Health Organization statistics, retinoblastoma is more common in infants and very young children than in older children, which has aroused widespread attention in the medical profession (1). There are various treatment modalities for retinoblastoma including surgical treatment, radiation therapy, chemotherapy, and molecular targeted therapy $(2,3)$. Treatments inhibit tumor growth but have few effects on reducing the mortality of patients with advanced cancer.

The initiation of cell cycle arrest, apoptosis and autophagy are the important strategies in cancer treatment as well as prevention. The cell cycle is the series of events that take place in a cell leading to its division to produce two daughter cells. Apoptosis is a process of programmed cell death that occurs in multicellular organisms. Autophagy is the natural, regulated, destructive mechanism of the cell that disassembles unnecessary components. Various studies highlight that the therapeutic agents to treat cancer act by inhibiting cell cycle, apoptosis, and autophagy $(4,5)$. These agents affect the cell cycle and cause autophagy through multi-signaling pathways within the cells. The PI3K/AKT/mTOR pathway is an intracellular signaling pathway important for regulating the cell cycle, autophagy, cell survival, proliferation, differentiation, apoptosis, metabolism, and quiescence $(6,7)$. The abnormal P13K/ AKT/mTOR signaling pathway leads to reduce apoptosis and increase proliferation and is the main cause of cell carcinogenesis, tumor invasion, metastasis, and drug resistance. The abnormalities of this signaling pathway are common in breast cancer, lung cancer, liver cancer, melanoma, cervical cancer, and rhabdomyosarcoma (8-12). Therefore, the investigation of P13K/AKT signaling pathway in retinoblastoma cells would be helpful to develop a new strategy to treat retinoblastoma.

2-Methyl-2-butanol (MBT) is a branched pentanol. It is a colorless flammable liquid with a pungent odor of camphor, used primarily as a pharmaceutical or pigment 
solvent and as a raw material for synthetic perfumes and pesticides. MBT is also found in a variety of traditional Chinese medicines. In recent years, MBT has drawn more attention because of its wide use in industry, agriculture and medicine. Our previous study reported that MBT has anticancer properties under low concentration in HXORB44 cells. Moreover, it can be conveniently used in the eye for treatment of retinoblastoma. However, the detailed mechanisms of MBT action for the treatment of retinoblastoma are not well understood.

The present study was designed to investigate the anti-cancer effect as well as the molecular mechanisms of MBT to induce cell cycle arrest and autophagy in HXORB44 human retinoblastoma cells.

\section{Material and Methods}

\section{MTT assay}

We used the HXO-RB44 retinoblastoma cell line in this study. These cells were obtained from Sciencell Research Laboratories (USA). Primary normal retinal Miller cells were purchased from Meiyan Biotechnology (China). The cells

A
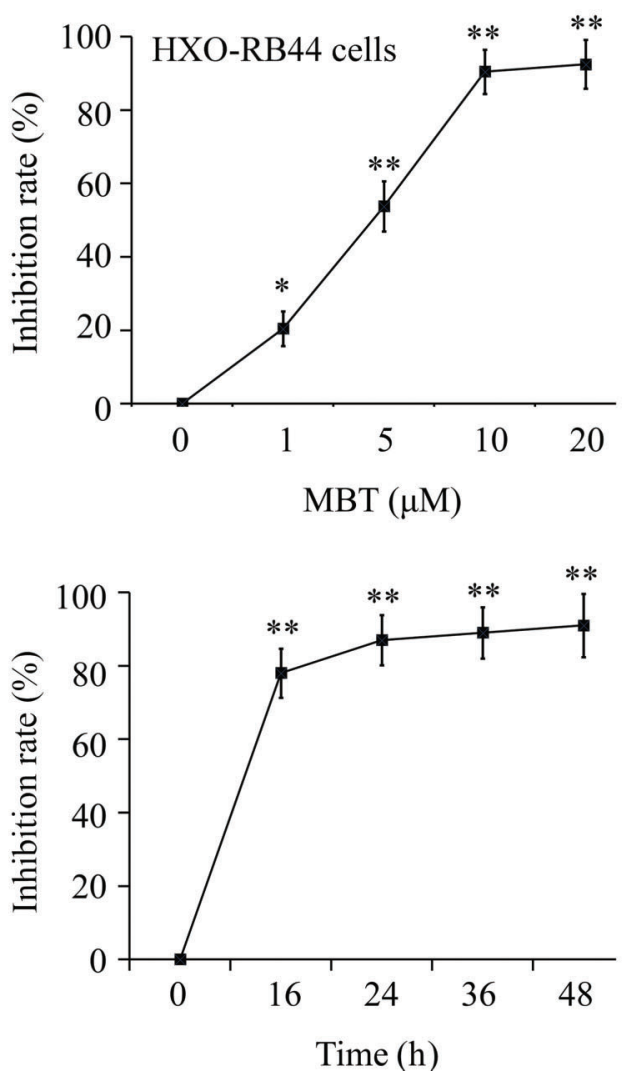

were cultured with L-glutamine and sodium pyruvate in Dulbecco's Modified Eagle's medium (DMEM; Sciencell Research Laboratories) with supplementation of $12 \%$ inactivated fetal bovine serum (FBS), $100 \mathrm{U} / \mathrm{mL}$ penicillin, and $100 \mu \mathrm{g} / \mathrm{mL}$ streptomycin at $37^{\circ} \mathrm{C}$ and $5 \% \mathrm{CO}_{2}$. MBT was obtained from Yancheng China Biotechnology Co. Ltd. (China). The HXO-RB44 and Miller cells were seeded onto 96 -well plates $\left(10^{4}\right.$ cells) and treated with $\mathrm{MBT}(0,1$, $5,10$, and $20 \mu \mathrm{M})$ for $16,24,36$, and $48 \mathrm{~h}$. MTT $(0.5 \mathrm{mg} / \mathrm{mL})$ was then added to each well for $3 \mathrm{~h}$. Then, $500 \mu \mathrm{L}$ of DMSO was added to dissolve the crystals. The absorption values were determined at $540 \mathrm{~nm}$ with an ELISA plate reader.

\section{Cell cycle assay}

The HXO-RB44 cells were plated at a concentration of $10^{6}$ cells/well in 6-well plates and incubated with MBT at $0,1,10$, and $20 \mu \mathrm{M}$ for $24 \mathrm{~h}$. Then, the cells were collected and washed with cold PBS. Afterwards, cells were centrifuged at $500 \mathrm{~g}$ for $10 \mathrm{~min}$ at room temperature and the pellet was fixed in $75 \%$ ethanol for $1 \mathrm{~h}$ at $4^{\circ} \mathrm{C}$ for $\mathrm{PI}$ (propidium iodide) staining. Then, the cells were washed with cold PBS and re-suspended in cold PI solution $(50 \mu \mathrm{g} / \mathrm{mL})$

B
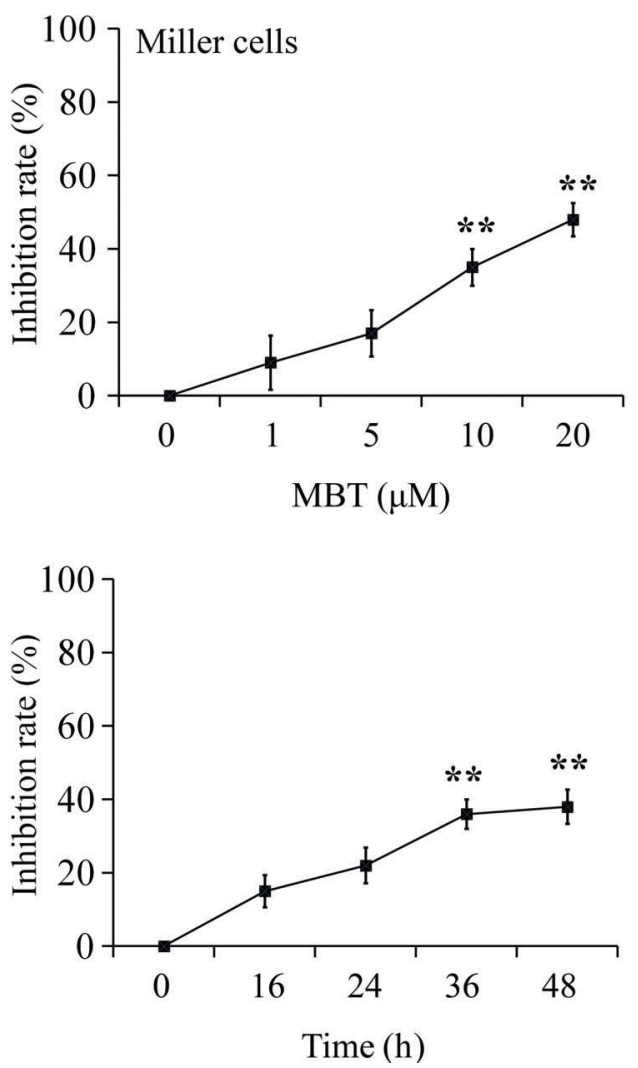

Figure 1. Effects of 2-methyl-2-butanol (MBT) on HXO-RB44 cells $(A)$ and Miller cells $(B)(n=6)$. Data are reported as means \pm SD. ${ }^{*} \mathrm{P}<0.05$ and ${ }^{* *} \mathrm{P}<0.01$ vs 0 (ANOVA). 
containing RNase A $(0.1 \mathrm{mg} / \mathrm{mL})$ in PBS, $\mathrm{pH} 7.4$, for $30 \mathrm{~min}$ in the dark.

\section{Cell apoptosis and necrosis}

Annexin $\mathrm{V}$ and $\mathrm{PI}$ double fluorescent staining was performed to detect cell apoptosis and necrosis. Normal living cells and early apoptotic cells resist staining by $\mathrm{PI}$, but necrotic cells are stained. Briefly, HXO-RB44 cells were cultured in medium with or without MBT $(20 \mu \mathrm{M})$. After $48 \mathrm{~h}$ of treatment, cells were washed twice with $0.01 \mathrm{M}$ PBS and suspended in $200 \mu \mathrm{L}$ binding buffer. Cells were then incubated with $10 \mu \mathrm{L}$ Annexin V-FITC and $5 \mu \mathrm{L}$ $\mathrm{PI}$ for $30 \mathrm{~min}$ at $4^{\circ} \mathrm{C}$ in dark room. Annexin V-FITC and PI fluorescence was immediately observed under confocal laser scanning microscope (Olympus, Japan). Bafilomycin A1 (autophage inhibitor) with a final concentration of $10 \mu \mathrm{M}$ was used to examine the MBT-induced autophage.

\section{Western blot analysis}

The HXO-RB44 cells were first seeded onto 6-well plates $\left(10^{6}\right.$ cells/well) and then treated with MBT at 0,1 , 10 , and $20 \mu \mathrm{M}$ for $24 \mathrm{~h}$. Total cell lysates were obtained after treatment with RIPA buffer and protease inhibitors. The protein concentrations were determined by Bradford protein assay (BioRad Lab., USA). Approximately $75 \mu \mathrm{g}$ of lysate was resolved on $12 \%$ SDS-PAGE, electrotransferred to PVDF membranes (Dingguo, China), and then incubated with specific primary rabbit polyclonal antibodies to cyclin B1, p27, and caspase- 3 at $4^{\circ} \mathrm{C}$ overnight. Caspase-9, LC3-I LC3-II, p-PI3K, and p-Akt were purchased from Abcam,
Shanghai, China. Antibody against $\beta$-actin and peroxidaselabeled anti-rabbit immunoglobulin were purchased from Boster (China) and an enhanced chemiluminescence (ECL) kit was purchased from Pierce (USA).

\section{PI3K/Akt agonist}

To identify the role of PI3K/Akt on MBT-induced cell cycle arrest and autophagy in HXO-RB44 cells, $10 \mu \mathrm{M}$ of SC79 (a specific Akt agonist) was pretreated $1 \mathrm{~h}$ before MBT (10 or $20 \mu \mathrm{M})$ treatment. SC79 was purchased from AMQUAR Life Science \& Biotechnology (China). The further experiments were conducted after incubation with MTB for $24 \mathrm{~h}$.

\section{Statistical analysis}

Data are reported as means $\pm S D$. Significant differences were determined using one-way ANOVA for multiple group comparison and Student's $t$-test for two group comparison. $\mathrm{P}<0.05$ was considered statistically significant.

\section{Results}

\section{MBT inhibited HXO-RB44 cell viability}

The results of the experiment showed that MBT significantly inhibited the proliferation of HXO-RB44 cells in a dose- and time-dependent manner where 50\% inhibitory concentration (IC50) was estimated approximately at $5 \mu \mathrm{M}$ (Figure $1 \mathrm{~A}$ and $\mathrm{B}$ ). However, MBT had low cytotoxicity to Miller cells. These findings suggested that MBT had greater cytotoxicity to HXO-RB44 cells.
A

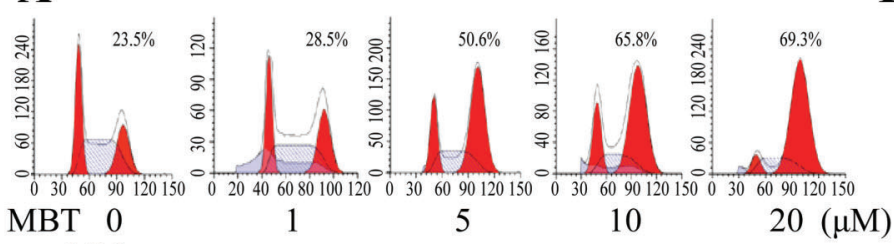

B

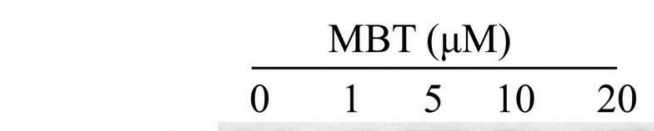

p 27

Cyclin B1 $\beta$-actin
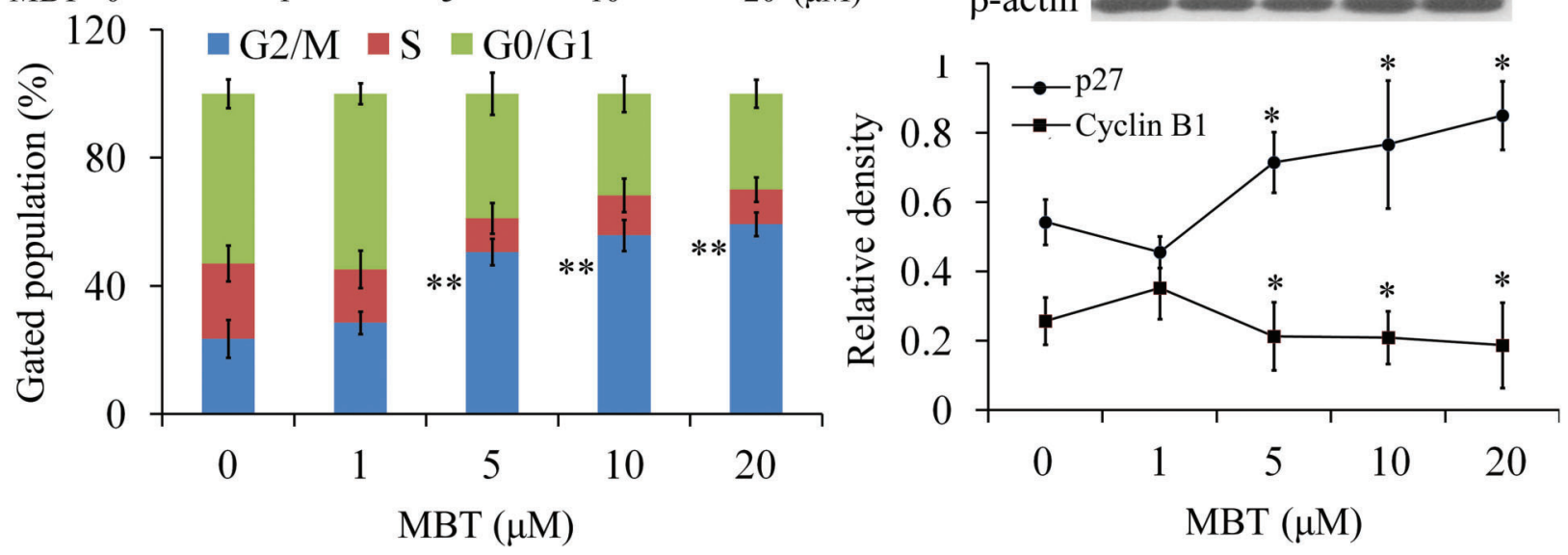

Figure 2. 2-Methyl-2-butanol (MBT) induced G2/M cell cycle arrest of HXO-RB44 cells ( $\mathrm{n}=4)$. $A$, Flow cytometry. $B$, Immunoblotting for p27 and cyclin B1. Data are reported as means \pm SD. ${ }^{*} \mathrm{P}<0.05$ and ${ }^{*} \mathrm{P}<0.01$ vs 0 (ANOVA). 


\section{MBT induced cell cycle arrest in HXO-RB44 cells}

The cells in the G2/M phase were significantly increased in a dose-dependent manner (Figure 2A). Western blot results showed that the $\mathrm{p} 27$ and cyclin $\mathrm{B} 1$ proteins are crucial in G2/M phase transition process. The results revealed that MBT increased p27 expression and decreased the expression levels of cyclin B1 protein in a dose-dependent manner at $24 \mathrm{~h}$ treatment (Figure 2B). These data suggested that MBT induced cell cycle arrest by regulation of $\mathrm{p} 27$ and cyclin B1 proteins in HXO-RB44 cells.

\section{MBT induced cell apoptosis and autophagy in HXO- \\ RB44 cells}

Apoptosis markers caspase- 3 and caspase- 9 and autophagy markers microtubule-associated protein1 light chain 3 (LC3) were analyzed by western blot. The results showed

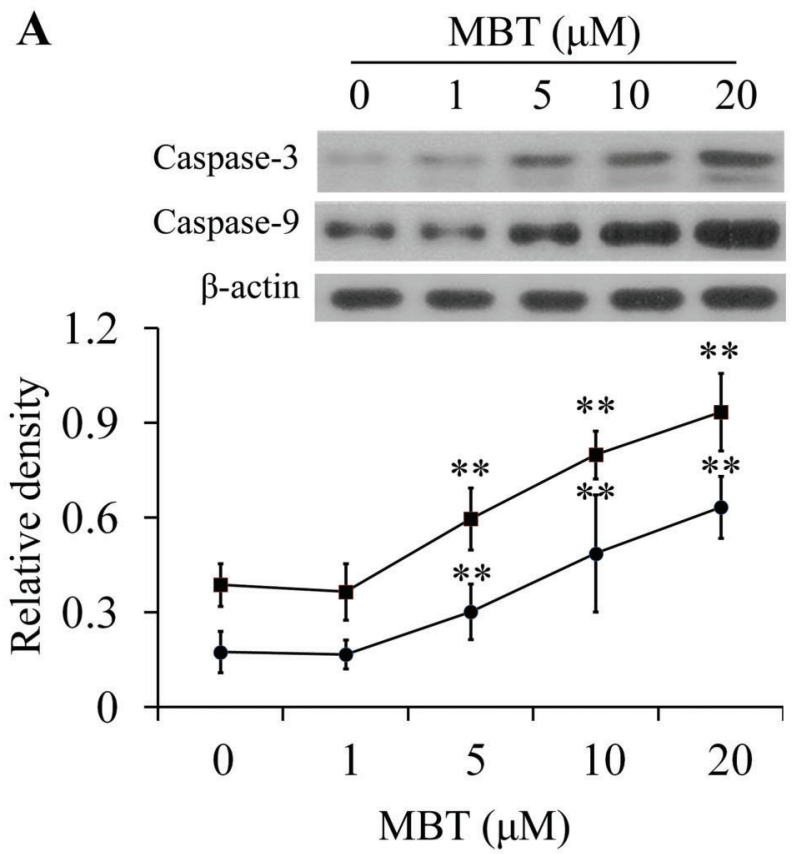

B

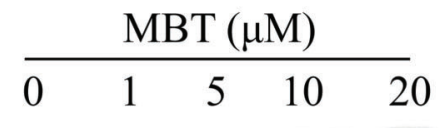

\section{LC3-I}

LC3-II

$\beta$-actin
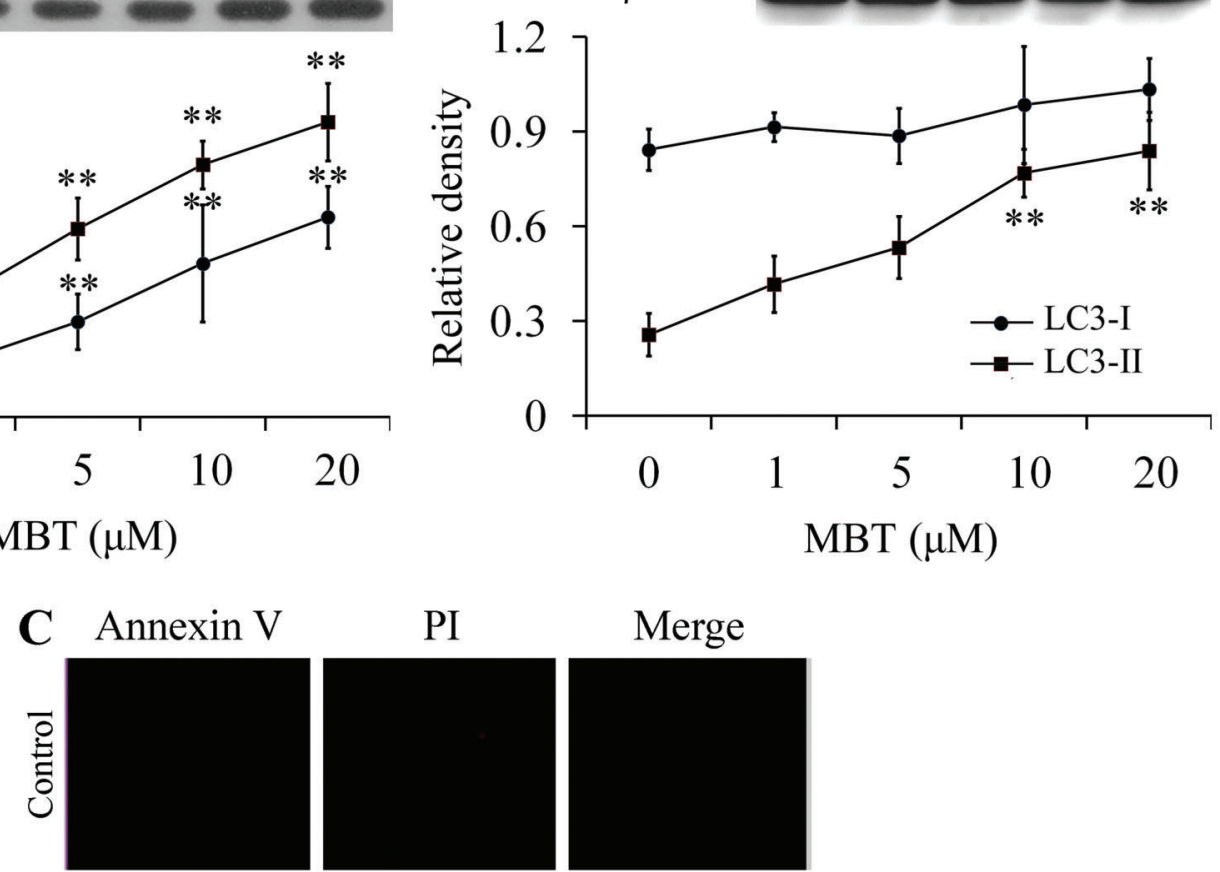

Merge
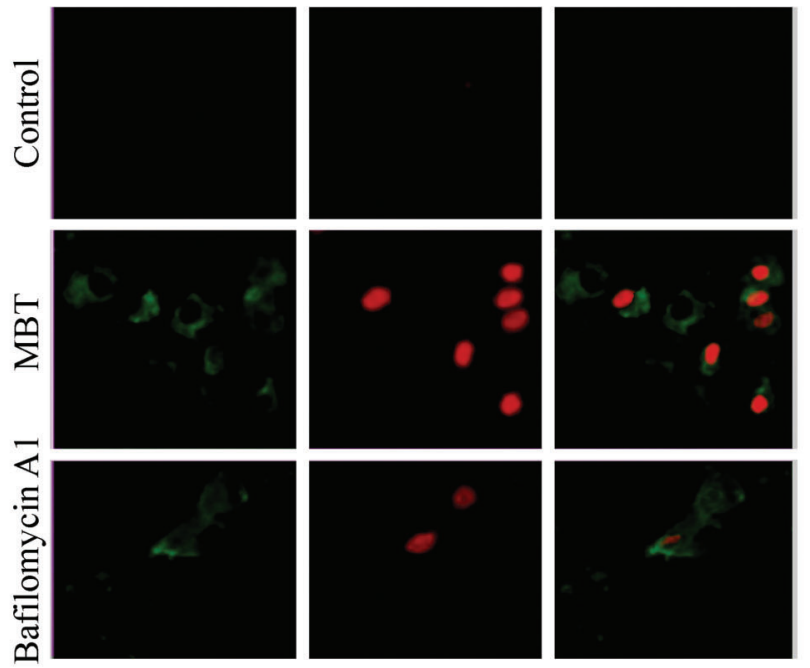

Figure 3. Apoptosis $(A)$ and autophagy markers $(B)$ in 2-methyl-2-butanol (MBT)-treated HXO-RB44 cells assayed by western blot $(n=4)$. Data are reported as means \pm SD. $C$, Apoptosis and necrosis detected by Annexin V-FITC and PI double fluorescence staining. ${ }^{* *} \mathrm{P}<0.01$ vs 0 (ANOVA). 
that MBT induced apoptosis in a dose-dependent manner (Figure 3A). During autophagy, a cytosolic form of LC3 (LC3-I) is conjugated to phosphatidylethanolamine to form membrane-bound form of LC3 (LC3-II). In this study, two variants of LC3 were detected by western blot and the ratio of LC3-II/LC3-I also showed an increase in a dosedependent manner (Figure 3B). Thus, the results suggested that MBT induced autophagy by promoting the conversion of LC3-I to LC3-II.

The results for apoptosis and necrosis markers Annexin V-FITC and PI double fluorescence staining showed that Annexin V-FITC and PI signals could barely be detected in control cells, while strong fluorescence densities were visible in response to MBT $(20 \mu \mathrm{M})$; apoptosis and necrosis could be blocked by Bafilomycin A1 (autophage inhibitor; Figure 3C).

\section{Involvement of PI3K/AKT pathway in MBT-induced effects}

Western blot revealed that MBT inhibited the activation of $\mathrm{p}-\mathrm{PI3K}$ and $\mathrm{p}$-Akt (Figure 4A). SC-79 reversed the cell cycle arrest induced by MBT (Figure 4B). In addition, SC-79 (specific Akt agonist) decreased the expression of p27 and promoted the expression of cyclin B1 in the MBT-treated
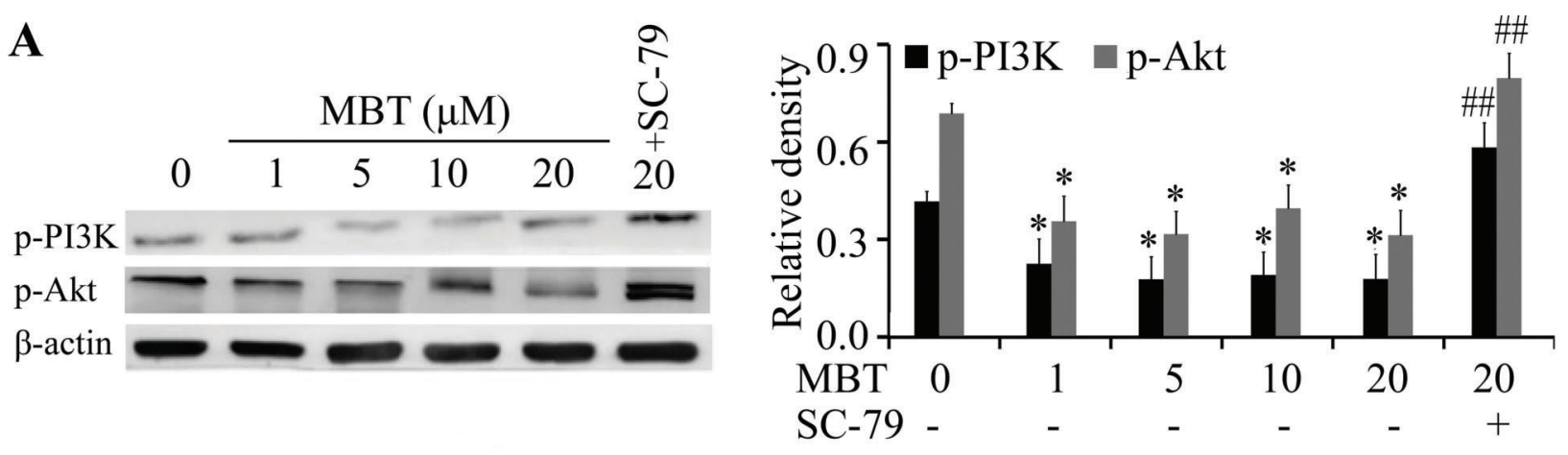

B

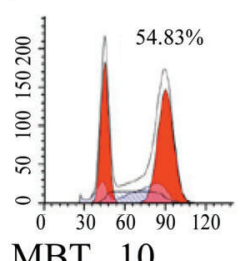

MBT 10

SC-79 -

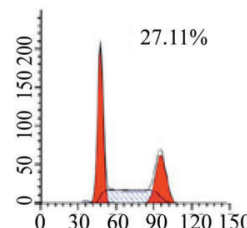

10

$+$

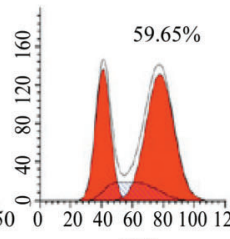

20

$-$

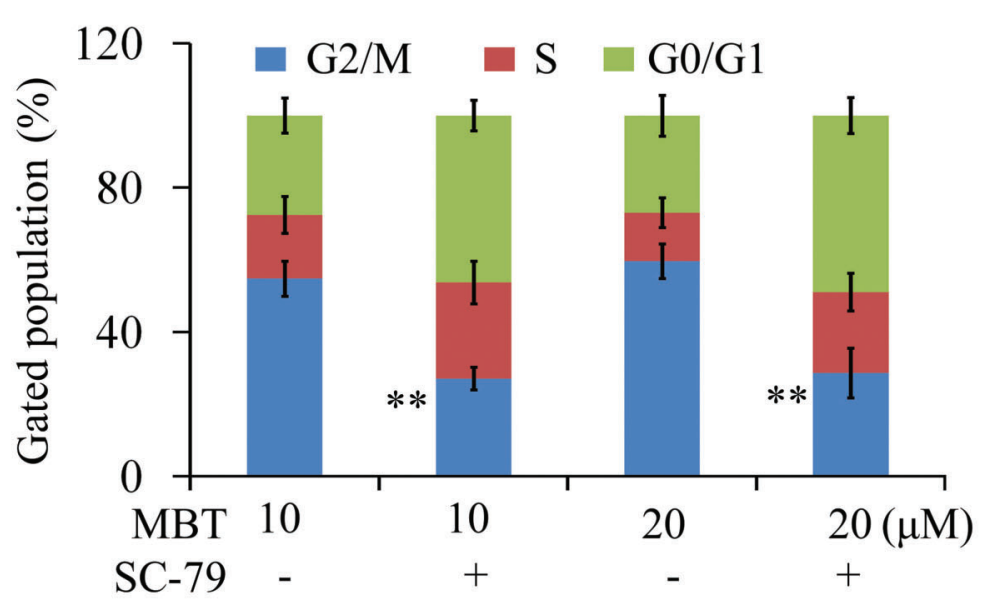

C

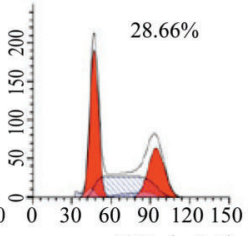

$\operatorname{MBT}(\mu \mathrm{M}) \quad 10 \quad 10 \quad 20 \quad 20$

$\mathrm{SC}-79-+\quad+$
p27

Cyclin B1

Caspase-3

Caspase-9

LC3-I

LC3-II

$\beta$-actin

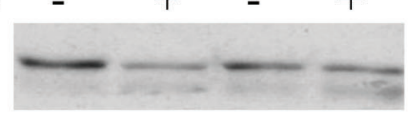

Figure 4. Role of PI3K/Akt in 2-methyl-2-butanol (MBT)-induced cell cycle arrest and autophagy in HXO-RB44 cells. $A$, Inhibition of p-PI3K and p-Akt in MBT-treated cells. ${ }^{*} \mathrm{P}<0.05$ vs 0 ; ${ }^{\# \#} \mathrm{P}<0.01$ vs MTB 20 (ANOVA and $t$-test). $B$, Effects of SC-79 on cell cycle arrest. ${ }^{* *} \mathrm{P}<0.01$ vs MTB 10 or MTB 20 (t-test). $C$, Effects of SC-79 on apoptosis and autophagy. Data are reported as means \pm SD. 
HXO-RB44 cells. It was also found that SC-79 inhibited the MBT-induced apoptosis and autophagy (Figure 4C). Hence, these findings suggested that PI3K/Akt pathway was involved in MBT induced G2/M arrest and autophagy.

\section{Discussion}

Retinoblastoma is a common ocular cancer in children that rapidly develops from the immature cells of the retina. MBT is a branched pentanol, colorless, and flammable liquid. It is common in organic solvents and widely used in the food industry, agriculture, and medicine. It is also found in a variety of traditional Chinese medicines. In our previous study, it was found that MBT has anti-cancer activity but the mechanisms are not well understood. It was also found that apart from abnormal cells, MBT also damages normal cells at higher concentrations. The present study was designed to investigate the anti-cancer effect of MBT on human retinoblastoma cells. The results highlight that MBT induced cell cycle arrest, apoptosis and autophagy by suppression of PI3K/Akt pathways in HXORB44 cells. This is the first report showing the anti-cancer mechanisms of MBT in HXO-RB44 cells, which induced G2/M cycle arrest and autophagy through PI3K/Aktmediated pathways.

The G2/M phase progression is controlled by cyclin B1 and CDK1 complex (13). Cyclin B is a mitotic cyclin and CDK1 is a highly conserved protein, which is a key player in cell cycle regulation. Cyclin-CDK1 phosphorylate proteins, which leads to cell cycle progression (14). The cyclin-dependent kinase (Cdk) inhibitor p27 is a cell cycle inhibitory protein that plays an important role in cell cycle arrest and hence inhibits cell proliferation. In our study, western blot results showed that MBT significantly increased p27 and decreased cyclin B1 protein expression in HXO-RB44 cells, which indicate that MBT-induced G2/M

\section{References}

1. Bhargav A, Singh U, Trehan A, Zadeng Z, Bansal D. Female Sex, bilateral disease, age below 3 years, and apprehension for enucleation contribute to treatment abandonment in retinoblastoma. J Pediatr Hematol Oncol 2017; 39: e249e253, doi: 10.1097/MPH.0000000000000856.

2. Mendoza PR, Grossniklaus HE. Therapeutic options for retinoblastoma. Cancer Control 2016; 23: 99-109, doi: 10.1177/107327481602300203

3. Grossniklaus HE. Retinoblastoma. Fifty years of progress. The LXXI Edward Jackson Memorial Lecture. Am J Ophthalmol 2014; 158: 875-891, doi: 10.1016/j.ajo.2014.07.025.

4. Li Y, Cui Y, Wang W, Ma M, Li M, Chen S. effect of the serum inhibited gene ( $\mathrm{Si} 1$ ) on Autophagy and apoptosis in MCF-7 breast cancer cells. Cell Physiol Biochem 2017; 41: 22682278, doi: 10.1159/000475644.

5. Visagie MH, van den Bout I, Joubert AM. A bis-sulphamoylated estradiol derivative induces ROS-dependent cell cycle arrest might be associated with down-regulation of cyclin B1 and CDK1 complex and up-regulation of p27.

Apart from G2/M arrest, MBT also induced apoptosis and autophagy. Caspase- 9 is an initiator caspase while caspase 3 protein plays a central role in the execution phase of cell apoptosis (6). Caspase- 9 and caspase- 3 are located upstream and downstream of the apoptosis cascade, respectively. Caspase- 3 is activated by caspase- 9 (15). MBT could induce apoptosis in HXO-RB44 cells by activating the caspase- 3 and -9 . Moreover, light chain 3 (LC3) is a soluble protein that helps to engulf cytoplasmic components, including cytosolic proteins and organelles during autophagy by autophagosomes and is widely used as a biochemical marker of autophagy (16). A marked conversion of free LC3-I to heavier lipid bound LC3-II was detected by western blot where the ratio of LC3-II/ LC3-I increased in a dose-dependent manner. In addition, MBT could induce apoptosis and necrosis, which could be reversed by autophage inhibitor bafilomycin A1. In our experiment, MBT dephosphorylated PI3K and Akt signaling pathway. PI3K/AKT/mTOR pathway is an intracellular signaling pathway important in regulating cell cycle, proliferation and apoptosis. A specific Akt agonist reversed MBT-induced cell cycle arrest, apoptosis, and autophagy in HXO-RB44 cells. Hence, these findings suggested that PI3K/Akt signaling pathway was involved in MBT-induced effects of HXO-RB44 cells. Thus, PI3K/Akt pathways might contribute to the MBT-induced apoptosis and autophagy.

In the present study, we focused on the mechanisms of the anti-cancer effect of MBT on human retinoblastoma cells to find a possible clinical application. Hence, we have demonstrated the anti-cancer mechanism for MBT-induced cell cycle arrest and autophagy in HXORB44 cells to be through inhibition of PI3K/Akt signaling pathway.

abnormalities and subsequent apoptosis. PLoS One. 2017; 12: e0176006, doi: 10.1371/journal.pone.0176006.

6. Kim SH, Son KM, Kim KY, Yu SN, Park SG, Kim YW, et al. Deoxypodophyllotoxin induces cytoprotective autophagy against apoptosis via inhibition of PI3K/AKT/mTOR pathway in osteosarcoma U2OS cells. Pharmacol Rep 2017; 69: 878-884, doi: 10.1016/j.pharep.2017.04.007.

7. Kumar D, Das B, Sen R, Kundu P, Manna A, Sarkar A, et al. Andrographolide Analogue induces apoptosis and autophagy mediated cell death in U937 Cells by Inhibition of PI3K/Akt/ mTOR pathway. PLoS One 2015; 10: e0139657, doi: 10.1371/ journal.pone.0139657.

8. Chen L, Jin T, Zhu K, Piao Y, Quan T, Quan C, et al. PI3K/ mTOR dual inhibitor BEZ235 and histone deacetylase inhibitor trichostatin a synergistically exert anti-tumor activity in breast cancer. Oncotarget 2017; 8: 11937-11949, doi: 10.18632/ oncotarget.14442. 
9. Zhu H, Liu Q, Tang J, Xie Y, Xu X, Huang R, et al. Alpha1ACT Functions as a tumour suppressor in hepatocellular carcinoma by inhibiting the pi3k/akt/mtor signalling pathway via activation of PTEN. Cell Physiol Biochem 2017; 41: 2289-2306, doi: 10.1159/000475648.

10. Caporali S, Alvino E, Lacal PM, Levati L, Giurato G, Memoli $D$, et al. Targeting the PI3K/AKT/mTOR pathway overcomes the stimulating effect of dabrafenib on the invasive behavior of melanoma cells with acquired resistance to the BRAF inhibitor. Int J Oncol 2016; 49: 1164-1174, doi: 10.3892/ijo. 2016.3594.

11. Tsai JP, Lee $\mathrm{CH}$, Ying TH, Lin CL, Lin CL, Hsueh JT, et al. Licochalcone $A$ induces autophagy through PI3K/Akt/mTOR inactivation and autophagy suppression enhances Licochalcone A-induced apoptosis of human cervical cancer cells. Oncotarget 2015; 6: 28851-28866, doi: 10.18632/oncotarget.4767.

12. Oudart JB, Doué M, Vautrin A, Brassart B, Sellier C, DupontDeshorgue $A$, et al. The anti-tumor NC1 domain of collagen XIX inhibits the FAK/PI3K/Akt/mTOR signaling pathway through $\alpha v \beta 3$ integrin interaction. Oncotarget 2016; 7: 15161528, doi: 10.18632/oncotarget.6399.

13. de Gooijer MC, van den Top A, Bockaj I, Beijnen JH, Würdinger $\mathrm{T}$, van Tellingen $\mathrm{O}$. The $\mathrm{G} 2$ checkpoint-a nodebased molecular switch. FEBS Open Bio 2017; 7: 439-455, doi: 10.1002/2211-5463.12206.

14. Shi H, Li Y, Ren X, Zhang Y, Yang Z, Qi C. A novel quinazoline-based analog induces G2/M cell cycle arrest and apoptosis in human A549 lung cancer cells via a ROSdependent mechanism. Biochem Biophys Res Commun 2017; 486: 314-320, doi: 10.1016/j.bbrc.2017.03.034

15. Akashi E, Fujihara S, Morishita A, Tadokoro T, Chiyo T, Fujikawa K, et al. Effects of galectin-9 on apoptosis, cell cycle and autophagy in human esophageal adenocarcinoma cells. Oncol Rep 2017; 38: 506-514, doi: 10.3892/or.2017.5689.

16. Shen W, Zhang X, Fu X, Fan J, Luan J, Cao Z, et al. A novel and promising therapeutic approach for NSCLC: recombinant human arginase alone or combined with autophagy inhibitor. Cell Death Dis 2017; 8: e2720, doi: 10.1038/ cddis.2017.137. 